\title{
Diagnostic Accuracy of Fiber Optic Laryngoscopy
}

\author{
Rabia Zaman Khan ${ }^{1}$, Asim Iqbal'2, Ghulam Saqulain ${ }^{3}$ \\ ${ }^{1}$ Assistant Professor, Department of ENT, Sir Ganga Ram Hospital Lahore, Punjab Pakistan \\ ${ }^{2}$ Professor, Department of ENT, Sir Ganga Ram Hospital, Lahore, Punjab Pakistan \\ ${ }^{3}$ Head of Department \& Associate Professor of Otorhinolaryngology, Capital Hospital PGMI, Islamabad, Pakistan
}

\section{A B STRACT}

Background: Laryngeal examination of patients with hoarseness is essential to diagnose a wide range of pathologies. Laryngeal visualization has progressed from simple indirect mirror examination to virtual laryngoscopy with flexible fiber optic laryngoscope as an acceptable option. This study was done to determine the diagnostic accuracy of fiber optic laryngoscopy in patients with hoarseness.

Material and Methods: This cross-sectional comparative study included a sample of 155 participants, of both genders, aged 20 to 60 years with hoarseness of at least 1 month duration. Participants were recruited through non probability consecutive sampling technique from ENT department, Sir Ganga Ram Hospital Lahore, Pakistan over a period of six months (October 2015 to March 2016). Patients fulfilling the selection criteria were subjected to Fiber Optic Laryngoscopy (FOL) under local anesthesia followed by Direct Laryngoscopy (DL) under general anesthesia and findings recorded. Data was collected, tabulated and analyzed using SPSS 17. Diagnostic value of FOL versus DL was calculated with frequency, percentage, sensitivity, specificity, positive predictive value (PPV) and negative predictive value (NPV). Results: Out of 155 participants, 48.39\% ( $n=75)$ were males and $51.61 \%(n=80)$ females, with mean age of $31 \pm 9.54$ years. Assessment of diagnostic accuracy of fiber optic laryngoscopy taking direct laryngoscopy as criterion standard showed an accuracy of $80.65 \%$ with $89.19 \%$ sensitivity, $77.96 \%$ specificity, $55.93 \%$ PPV, and $95.83 \%$ NPV, respectively. Conclusions: Fiber optic laryngoscopy is an excellent tool for the diagnosis of hoarseness, with a diagnostic accuracy of $80.65 \%$.

Key words: Direct laryngoscopy, Diagnostic accuracy, Fiber optic laryngoscopy, Hoarseness.

Authors' Contribution:
${ }^{1}$ Conception; Literature research;
manuscript design and drafting; ${ }^{2,3}$ Critical
analysis and manuscript review; Data
analysis; Manuscript Editing.

Cite this article. Khan RZ, Iqbal A, Saqulain G. Diagnostic Accuracy of Fiber Optic Laryngoscopy. J Islamabad Med Dental Coll. 2021; 10(2): 101-104. Doi: 10.35787/jimdc.v10i2.426
Correspondence:

Ghulam Saqulain

Email: Ghulam_saqulain@yahoo.com
Article info:

Received: October 2,2019

Accepted: June 18, 2021

\section{Introduction}

Hoarseness, a symptom which points to laryngeal dysfunction, is described by the patients as an altered voice quality. Diagnosis of hoarseness of more than one-month duration is important because a number of pathologies can cause hoarseness ranging from common cold to malignancy. ${ }^{1}$ Persistent hoarseness may result from morphologic changes due to benign vocal cord lesions (nodules and polyps) or malignant pathology (squamous cell carcinoma of larynx). ${ }^{2}$ Laryngoscopy is visual evaluation of larynx and is essential for the diagnosis of hoarseness. For this the armamentarium has progressed from Garcia's original indirect mirror laryngoscopy (IDL), direct 
laryngoscopy (DL) to virtual laryngoscopy (VL). 3,4 Although excessive gag reflex may make it intolerable in some (15\%) patients, ${ }^{5}$ the usefulness and cost effectiveness of indirect mirror laryngoscopy makes it a commonly used procedure as it can be easily performed by an otolaryngologist in the clinic. ${ }^{6}$ Both mirror laryngoscopy and FOL are indirect methods of laryngeal examination. ${ }^{7} \mathrm{~A}$ number of indirect fiber optic laryngoscopes such as the flexible fiber optic bronchoscope and nasopharyngoscope are not only good alternatives to $\mathrm{DL}$ but are found to be superior to mirror IDL as well. ${ }^{8} \mathrm{FOL}$ is also said to be a safer and non-invasive procedure to evaluate vocal cord paralysis and other laryngeal lesions. ${ }^{9}$ Keesecker and colleagues however, pointed out that it showed high frequency of error in diagnosis. ${ }^{10}$

There is much debate in the existing literature and varied recommendations by the practitioners regarding suitability and diagnostic accuracy of various methods of laryngeal examination. We planned this study to determine the diagnostic accuracy of fiber optic laryngoscopy in patients with hoarseness considering the direct laryngoscopy as criterion standard.

\section{Material and Methods}

In this cross-sectional comparative study, 155 participants were enlisted through non-probability consecutive sampling at the department of ENT, Sir Ganga Ram Hospital Lahore, Pakistan from October 2015 to March 2016. Approval was obtained from ethics committee of Sir Ganga Ram hospital. Sample size of 152 was calculated with hypothesized expected sensitivity of 70 and specificity of 99 using Wan Nor Arifin online calculator, ${ }^{11}$, with $5 \%$ precision and 95\% level of significance, taking prevalence of hoarseness as $11.4 \% .{ }^{12}$

Patients of both genders presenting with hoarseness of at least one-month duration with age between 20 to 60 years were included in the study. Patients unfit for general anesthesia, allergic to lignocaine or those who did not consent for participation were excluded from the study. After informed consent and explaining the procedure a detailed history, including socio-demographic information was recorded by the investigator. Before undergoing FOL, nasal decongestant drops (xylometazoline) and $4 \%$ lignocaine were administered to every patient. FOL was carried out with XION nasopharyngoscopy model EF-N, D: $3.4 \mathrm{~mm}$, L: $320 \mathrm{~mm}$, Direction of View: $0^{\circ}$, Angle of field of view: $80.0^{\circ}$, Depth of focus: 1 $50 \mathrm{~mm}$, Angle: $130^{\circ} / 130^{\circ}$ with complete visual system. Larynx was examined after passing the flexible scope from the nasal cavity to the throat, findings noted from the video monitor and sketches were drawn for record by the researcher. Next, the patients were admitted for DL under general anesthesia (GA). FOL findings were not shared with the surgeon to avoid bias. The findings of both the procedures were compared.

Data analysis was done using SPSS 17. Variables specially studied included diagnostic accuracy of FOL versus $\mathrm{DL}$ and presented by frequency, and percentages. $2 \times 2$ contingency tables were used to calculate the sensitivity, specificity, positive predictive value (PPV) and negative predictive value (NPV) of FOL compared to DL.

\section{Results}

The ratio of male to female participants was roughly equal $48.39 \%(n=75)$ versus $51.61 \%(n=80)$ with the mean age of $31.01 \pm 9.54$ years (Table I). DL (criterion standard) proved to be diagnostic in $23.87 \%(n=37)$ while in $76.13 \%(n=118)$ cause of hoarseness could not be identified (Table II). FOL picked up pathologies in additional $16.13 \%(n=26)$ patients and was found to have a diagnostic accuracy of $80.65 \%$ compared to the $\mathrm{DL}$, while the sensitivity was $89.19 \%$, specificity $77.96 \%$, PPV $55.93 \%$ and NPV of 95.83\% (Table II). 


\begin{tabular}{|l|c|c|c|}
\hline \multicolumn{4}{|c|}{ Table I: Frequency distribution of gender and age } \\
groups (n= 155) \\
\hline Variable & Group & $\begin{array}{c}\text { Absolute } \\
\text { Frequency } \\
\text { (\%) }\end{array}$ & $\begin{array}{c}\text { Relative } \\
\text { Frequency } \\
\text { (\%) }\end{array}$ \\
\hline Gender & Male & 75 & 48.39 \\
\cline { 2 - 4 } & Female & 80 & 51.61 \\
\hline $\begin{array}{l}\text { Age } \\
\text { (Years) }\end{array}$ & $20-30$ & 87 & 56.13 \\
\cline { 2 - 4 } & $31-65$ & 68 & 43.87 \\
\hline
\end{tabular}

\begin{tabular}{|c|c|c|c|}
\hline $\begin{array}{l}\text { Fiber optic } \\
\text { Laryngoscopy }\end{array}$ & \multicolumn{2}{|c|}{ Direct Laryngoscopy } & Total \\
\hline Positive & $\begin{array}{c}\text { True } \\
\text { positive(a) } \\
33\end{array}$ & $\begin{array}{c}\text { False } \\
\text { positive (b) } \\
26\end{array}$ & $a+b=59$ \\
\hline Negative & $\begin{array}{c}\text { False } \\
\text { negative(c) } \\
4\end{array}$ & $\begin{array}{c}\text { True } \\
\text { negative } \\
\text { (d) } 92\end{array}$ & $c+d=96$ \\
\hline Total & $a+c=37$ & $b+d=118$ & 155 \\
\hline
\end{tabular}

Sensitivity = 89.19\%; Specificity = 77.96\%; PPV = 55.93\%; NPV $=95.83 \%$; Diagnostic Accuracy $=80.65 \%$

\section{Discussion}

Present study revealed that FOL with a diagnostic accuracy of $80.65 \%$ picked up $16.13 \%$ more pathologies compared to DL and had a sensitivity of $89.19 \%$ and specificity of $77.96 \%$.

Williams et al. ${ }^{13}$ believed that FOL has revolutionized the laryngeal examination and operations. They compared FOL with indirect mirror and direct laryngoscopy in assessing various laryngeal disorders and found it a promising technique that in their opinion has an acceptable place in assessment of laryngeal disorders. The number of participants in our study is double to that of Williams et al. however, our findings are comparable to theirs in evaluation of FOL as a useful technique. Moser in his review termed FOL as a rapid, low risk diagnostic test for most common findings of laryngeal diseases in primary care setups. ${ }^{14}$ Mahbub and colleagues, compared FOL with IDL and found that FOL was superior to IDL for diagnosis of persistent upper airway symptoms. They recommended FOL in all patients with long-term progressive airway symptoms even if the mirror IDL appears normal. ${ }^{8}$ Although their focus was not diagnostic accuracy but only comparison of the percentage of lesions detected by both methods, nevertheless we believe our findings in terms of superiority of FOL holds true when we compared it with $\mathrm{DL}$, as it is now also being used for pediatric airway management. ${ }^{15}$ Shafi et al. also reported FOL as a safe and effective test for different ear, nose and throat pathologies. ${ }^{16}$ Similarly, in a local study by Hameed et al. with a sample size of 100 patients with hoarseness, it was noted that FOL was a safer, noninvasive procedure with only two patients requiring DL. ${ }^{9}$ According to Handler, FOL was test of choice for evaluation of pediatric larynx while DL was preferred in laryngotracheal surgery. ${ }^{17}$ Collins studied different laryngoscopy devices and concluded that the role and extent of FOL was not yet fully recognized in airway management. However, it was promising in respect of routine clinical examination, when laryngoscopy fails as well as for teaching purposes. ${ }^{18}$ Our study was unique because the participants were subjected to both FOL and DL for comparison rendering the results more reliable.

Cohen and Benyamini assessed the accuracy of Trans-nasal fiber optic laryngoscopy (TFL) versus DL by comparing the pathologic results of 110 laryngeal tissue biopsies. They found out that the sensitivity of TFL was $70.6 \%$ with a specificity of $96.7 \%$. Although they acknowledged the cost effectiveness and safety as positive aspect of the technique, they expressed concerns about its sensitivity and recommended that suspicious lesion diagnosed by TFL biopsy must undergo DL for confirmation. ${ }^{19}$ Our results nevertheless are conclusive in superiority of FOL over DL with a sensitivity of $80.19 \%$. 
The results of our study reveal that FOL is an essential tool for diagnosis of voice disorders and has an excellent accuracy for the diagnosis of diseases causing hoarseness. Therefore, we recommend FOL laryngoscopy for all patients presenting with hoarseness.

This study has a limitation of a small sample collected from a single hospital only, hence the results cannot be generalized. Another limitation is inclusion of patients with hoarseness only. Studies with large sample size including patients with all phonation disorders need to be conducted, which will give a more reliable account of accuracy of fiber optic laryngoscopy.

\section{Conclusion}

We concluded that in patients with hoarseness, fiber optic laryngoscopy with a diagnostic accuracy of $80.65 \%$ and taking direct laryngoscopy as criterion standard is an excellent diagnostic tool.

\section{References}

1. Sadoughi B, Fried MP, Sulica L, Blitzer A. Hoarseness evaluation: a transatlantic survey of laryngeal experts. Laryngoscope. 2014; 124(1): 221-6. Doi: 10.1002/lary.24178.

2. Mau T. Diagnostic evaluation and management of hoarseness. Med Clin North Am. 2010; 94(5): 945-60. Doi: 10.1016/j.mcna.2010.05.010.

3. Jahn A, Blitzer A. A short history of laryngoscopy. Logoped Phoniatr Vocol. 1996; 21(3-4): 181-5. Doi: 10.3109/14015439609098887.

4. Ragheb AS, El-Gerby KM, Ahmed AF, El-Anwar MW, El-monaem SA. Conventional endoscopy versus virtual laryngoscopy in assessment of laryngeal lesions. Egypt J Radiol Nucl Med. 2013; 44(3): 497503.

5. Yamamoto K, Tsubokawa T, Shibata K, Ohmura S, Nitta S, Kobayashi T. Predicting difficult intubation with indirect laryngoscopy. Anesthesiology. 1997; 86(2): 316-21. Doi: 10.1097/00000542-19970200000007.

6. Onotai LO, Nwosu C. Laryngoscopy: appraisal of 202 procedures carried out in two centers in Port
Harcourt, Nigeria. TNHJ. 2017; 17(1). https://www.ajol.info/index.php/nhj/article/view/1 54263/143844.

7. Pieters BM, Eindhoven GB, Acott C, van Zundert AA. Pioneers of laryngoscopy: indirect, direct and video laryngoscopy. Anaesth Intensive Care. 2015; 43 Suppl 4-11. Doi: $10.1177 / 0310057 \times 150430 s 103$.

8. Mahbub S, Al-Amin A, Biswas SS, Jamal MS. A Study on Diagnostic Importance of Fiber Optic Laryngoscopy (FOL) in Patients with Upper Airway Disorders. J Bangladesh Coll Phys Surg. 2014; 32(4): 200-5. Doi: 10.3329/jbcps.v32i4.26082.

9. Hameed A, Sheikh SI, Aziz B, Mushwani M. Vocal cord paralysis in 100 hoarse patients examined through flexible fibreopptic nasopharyngoscope/ laryngoscope. PJMHS. 2014; 8(1): 149-51.

10. Keesecker SE, Murry T, Sulica L. Patterns in the evaluation of hoarseness: time to presentation, laryngeal visualization, and diagnostic accuracy. Laryngoscope. 2015; 125(3): 667-73. Doi: 10.1002/lary.24955.

11. Buderer NM F. Statistical methodology: I. Incorporating the prevalence of disease into the sample size calculation for sensitivity and specificity. Acad Emerg Med. 19996; 3(9): 895-900.

12. Tavares EL, Brasolotto A, Santana MF, Padovan CA, Martins RH. Epidemiological study of dysphonia in 412-year-old children. Braz J Otorhinolaryngol. 2011; 77(6): 736-46.

13. Williams GT, Farquharson IM, Anthony J. Fibreoptic laryngoscopy in the assessment of laryngeal disorders. J Laryngol Otol. 1975; 89(3): 299-316. Doi: 10.1017/s0022215100080403

14. Moser SE. Nasolaryngoscopy. Prim Care. 2014; 41(1): 109-13. Doi: 10.1016/j.pop.2013.10.009.

15. Gupta A, Sharma R, Gupta N. Evolution of videolaryngoscopy in pediatric population. J Anaesthesiol Clin Pharmacol. 2021; 37: 14-27.

16. Shafi M, Shaikh AA, Ahmed J. Flexible Fiberoptic Naso-pharyngo-laryngosccopy: Indications and Outcome. J Surg Pak. 2015; 20(2): 56-59.

17. Handler SD. Direct laryngoscopy in children: rigid and flexible fiberoptic. Ear Nose Throat J. 1995; 74(2): 100-4.

18. Collins SR. Direct and Indirect Laryngoscopy: Equipment and Techniques. Respiratory Care. 2014; 59(6): 850-64.

19. Cohen JT, Benyamini L. Transnasal Flexible Fiberoptic in-office Laryngeal Biopsies-Our Experience with 117 Patients with Suspicious Lesions. Rambam Maimonides Med J. 2014; 5(2): e0011. Doi: 10.5041/RMMJ.10145. 